\title{
SOLAR SYSTEM VLBI ASTROMETRY: THE VENUS BALLOON EXPERIMENT
}

\author{
R. A. Preston, J. Ellis, S. G. Finley, C. E. Hildebrand, G. H. \\ Purcell, Jr., C. T. Stelzried, Jet Propulsion Laboratory; \\ R. Z. Sagdeev, V. M. Linkin, V. V. Kerzhanovich, L. R. Kogan, \\ V. I. Kostenko, L. I. Matveenko, R. R. Nazirov, S. V. Pogre- \\ benko, I. A. Strukov, Space Research Institute, Moscow, \\ USSR; J. E. Blamont, Centre National d'Etudes Spatiales, \\ Paris, France; N. Armand, Yu. N. Alexandrov, Institute of \\ Radio Electronics, Moscow, USSR; L. Boloh, G. Laurans, \\ Centre National d'Etudes Spatiales, Toulouse, France; \\ G. Petit, Institut Geographique National, Saint-Mande, \\ France; A. F. Bogomolov, Energy Institute, Ministry of \\ High Education, Moscow, USSR; I. G. Moiseev, Crimean \\ Astrophysical Institute, Simeiz, USSR; F. Biraud, A. Bois- \\ chot, A. Ortega-Molina, C. Rosolen, Observatoire de Paris- \\ Meudon, Meudon, France; P. Kaufmann, Itapetinga Radio \\ Observatory, Instituto de Pesquisas Espaciais, Sao Paulo, \\ Brazil.
}

ABSTRACT. A global array of 20 radio observatories was used to measure the three-dimensional position and velocity of the two meteorological balloons that were injected into the equatorial region of the Venus atmosphere by the VEGA spacecraft.

Previous Venera and Pioneer Venus probes into the Venus atmosphere have determined essentially instantaneous vertical profiles of the wind, showing a wind speed ranging from about $100 \mathrm{~m} / \mathrm{sec}$ at the visible top of the clouds (about $65 \mathrm{~km}$ altitude) to near zero at the surface. The VEGA balloons provided a means of measuring variations in the wind and in situ parameters at a nearly constant altitude below the tops of the clouds.

At least three antennas had to observe simultaneously each balloon and its associated flyby spacecraft at $1.7 \mathrm{GHz}$ to determine a complete set of three-dimensional position and velocity components relative to Venus. Plane-of-sky balloon velocity information was obtained by VLBI observations of the balloon carrier signal, where the measured quantity was the difference of the phase rates of the signals received at different sites. The line-of-sight velocity component was derived from measurements of the carrier Doppler shift at a single antenna. Measurements of altitude by a pressure sensor provided an independent means of determining the radial velocity component, and allowed a calibration of the frequency of the onboard oscillator which controlled the balloon transmissions. Plane-of-sky balloon 
position was obtained by VLBI observations of two coherent tones transmitted by the balloons, where the measured quantity was the received phase difference between the two tones, differenced again between sites. The radial component of position was derived from the pressure measurements.

To obtain both components of transverse position and velocity it was necessary to perform the VLBI observations on at least two baselines with large orthogonal components. For these VLBI measurements, simultaneous observations were also made of identical signals from the flyby spacecraft (in the same antenna beam as the balloon). When the balloon and flyby measurements were differenced, the effects of several error sources cancelled, providing precise measurements of balloon position and velocity relative to the flyby. An independent determination of the trajectory of the flyby relative to Venus was used to infer balloon position and velocity relative to a Venus-centered reference frame.

The total array of 20 ground antennas allowed simultaneous observations with good baseline geometry for 22 hours each day. Velocity measurements were made during each transmission from the balloons (every half hour or hour), while position measurements were possible only every 2 hours. For a single transmission, the typical one-sigma accuracies are about 1 $\mathrm{m} / \mathrm{sec}$ and $15 \mathrm{~km}$, respectively.

Initial analysis of the VLBI, Doppler and in situ data has provided preliminary scientific results. Each balloon was blown westward about 11,500 $\mathrm{km}(8,000 \mathrm{~km}$ on the night side) by zonal winds with a mean speed of about 70 $\mathrm{m} / \mathrm{sec}$ at the float altitude of $54 \mathrm{~km}$. The wind speed varied as much as several meters per second on time scales of tens of seconds to hours. Correlation of vertical velocity and temperature variations revealed an upward convective mean heat flow of 70 watts per square meter and the existence of gravity waves. There was also possible evidence of a solar-fixed atmospheric feature and topography-induced wind turbulence. Future analysis is expected to provide more complete descriptions of the dynamical processes that drive the atmosphere and the transports of heat and momentum. An understanding of these processes is essential to an adequate explanation of the high temperatures of the lower atmosphere and the high wind velocities of the upper atmosphere. 